\title{
Challenge and Coping Strategies of College English Education under the Background of MOOC Era
}

\author{
Qian Zhao \\ Shandong Xiehe University, Shandong, 250107, China
}

Keywords: MOOC era; college English; educational development; opportunity; challenge

Abstract: With the further strengthening of the globalization trend and the deepening of China's opening-up to the outside world, all levels of colleges and universities have strengthened the discussion of English teaching mode in the process of teaching. At present, the continuous integration of science and technology and education industry has prompted the education sector in China to strengthen the promotion and application of the MOOC teaching model. Based on this, this paper analyzes and discusses the challenges faced by college English teaching activities in the context of MOOC era, and analyzes the countermeasures. It is hoped to provide multiple teaching modes for college English education.

Due to the development of the times and the advancement of educational technology, the teaching staff of our country realized the integration of the resources of famous schools and famous teachers with the help of the network platform, and promoted the creation of online courses and personalized flexible learning modes. In fact, this MOOC model tends to have a greater impact on traditional university education in the process of widespread promotion. Based on this, in the process of carrying out college English teaching activities, it is necessary to strengthen the analysis of the MOOC model, and scientifically and properly handle the impacts and problems caused by it, and ensure the sustainable development of college English teaching activities. This provides a complete learning experience and learning method not only on the Internet to establish a platform for free communication, quality education resources for online education, centralized teaching, interaction between teachers and students. MOOC has quickly passed, and it has been developed for two years and is widely regarded in the world as "the most profound technological change in the field of higher education in the past 500 years."

\section{Mooc Mode Overview}

The so-called MOOC, refers to the large open online course (massive open online courses), the teaching model was originally co-founded by top American universities to provide more channels and learning resources for learners. In the process of implementation, this model can bring university education into the " $4 \mathrm{~A}$ era", ensuring that students can learn the content of the course they are interested in anytime and anywhere[1].

In general, MOOC model in the promotion process, generally have four characteristics, namely, the diversification of teaching tools, resources, and second, curriculum resources easy to use, the 
third is of course a wider audience, Fourth Class Participation autonomy Strong. It is precisely because the MOOC model has many advantages in the process of implementation, so it is favored by learners, and has a certain impact on the traditional teaching mode in the process of promotion and application[2].

\section{Development Opportunities for College English Teaching in the Age of MOOC}

With the promotion of the MOOC teaching model, China's college English courses are facing new opportunities in the process of development, which contributes to the efficiency and quality of the course teaching. In this regard, the author summarizes the development opportunities of college English teaching in the era of MOOC. The specific contents are as follows:

\subsection{Realize the Individualized and Innovative Development of College English Education}

In fact, the MOOC teaching model often uses the network and multimedia platforms as the medium of communication in the process of promotion. Therefore, it has rich educational resources in the implementation process, and can break the time and space restrictions of teaching. Students can choose to learn according to their own interests. Courses to meet the individual needs of students. In addition, the courses in the MOOC mode are often student-centered in the setting of teaching content, which fully mobilizes students' interest and enthusiasm for learning, and further enhances the humanization level of the course teaching. At the same time, the model often interacts with students in a multi-faceted and multi-angled manner, and integrates multiple assessment mechanisms, thus enabling the development of students' innovative abilities. The lack of educational resources is relative to the increase in admissions. This is a student of a personalized university. The university of humanitarian university English teaching, in fact, many universities and even large classes of up to 100 people will take the citizen English class. Teachers can't master each student's English learning situation, students' English learning enthusiasm and student initiative, and the empty promise "individuals" are reduced to solve in class, their own problems can not have one. According to the interest of their relevant English language courses to break the time and space of the educational platform and MOOC, students are constrained by the English situation to carry out their own learning progress, and selected, actually they learn English according to the specific situation, which is personalized, You can choose the time and place of the human way to improve the efficiency of students' English learning and improve their academic performance [3]. The following are the weights of related indicators.

Table 1 Weights of related indicators

\begin{tabular}{|c|c|c|c|}
\hline Index & Creative & Process & Popularization \\
\hline Weight & 0.4325 & 0.2374 & 0.2301 \\
\hline
\end{tabular}

\subsection{Optimize the teaching process}

When the MOOC model is implemented, it can often improve the situation that the content of the classroom teaching is single and backward. In fact, the MOOC course enriches the teaching content by means of the Internet and other platforms, and presents diverse characteristics in the teaching mode, which promotes the widening of teaching channels. This open teaching channel and method can, to a large extent, create a good teaching environment for students and promote the improvement of students' English proficiency. In addition, the MOOC model optimizes the English 
teaching process during the operation process and promotes the improvement of teaching efficiency [4].

\subsection{Promoting education popularization}

In the process of teaching and promotion, MOOC mode has realized the integration and dissemination of various teaching resources, and has realized the sharing of educational resources to a large extent, and provided a broad idea for the popularization and fair development of higher education. In addition, the MOOC model has the characteristics of " $4 \mathrm{~A}$ ", which breaks the time and space restrictions of students in remote areas and promotes the efficiency and quality of school teaching. The MOOC program covers a wide range of fields. At any university, it can match the top universities in the world. We can say that we have gathered quality education resources. First of all, the Chinese college students' MOOC can create a good environment for the development of learning English. At MOOC, the only Chinese students' English ability is enhanced, and the output and English input are increased instead of English. Pure foreign teachers and classmates Online communication is important, it is impossible. After some reforms, this is an educational model in which Chinese college English education is not really able to get rid of "subsidy". Teachers, students accept passive knowledge and are full of inefficiencies in the teaching process. The rise of the MOOC classroom has destroyed the college English teaching model. After that, students must be recommended as content for self-study on the Internet, or a question from the previous teacher. Use it in the classroom to guide students, further develop and apply knowledge, so that students learn to discuss, critical thinking and enhance students. Innovation, the actual student is the main body of learning, is the protagonist of the classroom[5].

\section{Challenges and Countermeasures of College English Teaching in the Age of MOOC}

\subsection{Monopolize a few quality education resources}

In fact, with the continuous promotion of the MOOC model, it can achieve the collection of educational resources for various countries and various types, and thus break the time and space restrictions of teaching. This situation often poses a challenge to the survival of the university. The MOOC model can also monopolize some high-quality resources in the process of implementation, which leads to the competitiveness of university education in some areas is lower than MOOC, which is not conducive to the sustainable development of university education. Based on this, in order to solve this problem, universities and colleges need to strengthen the introduction of teaching aids to achieve innovation and development of teaching media. In this process, college English teachers need to break the shackles of traditional teaching models and use the Internet to teach, so as to ensure the smooth flow of educational information and promote timely and effective communication with learners. In addition, university education in English, it is also related to the need to strengthen management, to ensure that knowledge of teaching English at the same time, strengthen the focus on moral education of students, to ensure the full development of students. When the classroom teaching activities of college English are carried out, they can often form a class style, realize the cultivation of students' personality, and ensure that they maintain their dominant position in the competition of the times. Here are a few of the objects that are being challenged. 


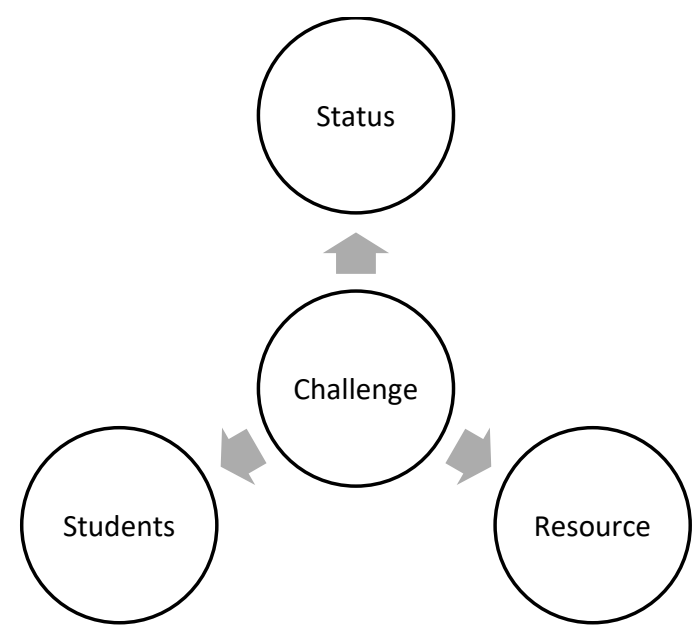

Figure 1 Objects that are being challenged

\subsection{The status of English teachers is affected}

China's colleges and universities mainly use the class teaching system to carry out teaching. In such a teaching environment, teachers often occupy the dominant position of the curriculum, and control the content and methods of the curriculum, which is not conducive to enhancing students' interest and enthusiasm for learning. The promotion of MOOC mode can often realize the construction of the student-based curriculum form, realize the improvement of classroom teaching efficiency, and bring impact to the authority of traditional university teachers. Based on this, under the influence of this model, college English teachers need to strengthen their own quality and skills to ensure the steady development of all work. In this process, teachers first need to strengthen the transformation of their own teaching roles, and gradually transition from teaching managers to service providers. In addition, because MOOC generally has the characteristics of interactivity in the process of learning, English teachers need to strengthen communication and cooperation with students in the process of changing their roles. Secondly, college English teachers need to adjust their teaching content, teaching time and teaching mode in the course of course teaching, and ensure that they learn knowledge based on teaching tasks and activities. Not only that, teachers need to evade the way of mechanical lectures, and strengthen the examination and evaluation of students' progress in learning, to ensure that students can have strong learning enthusiasm in this process, and promote the improvement of teaching effects. Finally, teachers need to strengthen their comprehensive quality, ensure that their teaching skills improve, and promote the improvement of comprehensive quality. Teachers need to have a wide range of comprehensive knowledge, and improve the ability to discriminate and integrate network resources, and organize classrooms with modern educational technology.

\section{Conclusion}

With the development of the times and the advancement of science and technology, China's college English teaching activities are facing certain challenges and opportunities in the process of development. In order to ensure the effectiveness of college English teaching, teaching staff must take scientific measures to meet the challenges. Based on this, this paper focuses on the analysis of the connotation of MOOC model, and discusses the development opportunities of college English teaching in the era of MOOC and the challenges and countermeasures of college English teaching in the era of MOOC. The author believes that with the implementation of relevant measures, China's college English teaching activities will certainly achieve significant development. 


\section{References}

[1]Wen Zhao,Boran Wang,David Coniam,Bingxue Xie. Calibrating the CEFR against the China Standards of English for College English vocabulary education in China [J]. Language Testing in Asia, 2017,7(1).

[2]Beth L. Vealé,Kevin R. Clark,Jeffrey B. Killion,Preet Sharma. The HESI Admission Assessment and Radiography Exit Examination as Predictors for Student Success [J]. Journal of Medical Imaging and Radiation Sciences, 2016.

[3]Todd M. Tartavoulle,Robin English,Tina Patel Gunaldo,Deborah Garbee,Donald E. Mercante,Sandra Carlin Andrieu, Jessica L. Johnson. Using the IDEA framework in an interprofessional didactic elective course to facilitate positive changes in the roles and responsibility competency [J]. Journal of Interprofessional Education \&amp; Practice, 2016,2.

[4]Alexander Y. Sheng, Alexandra Castro, Resa E. Lewiss. Awareness, Utilization, and Education of the ACR Appropriateness Criteria: A Review and Future Directions [J]. Journal of the American College of Radiology, 2016, 13(2).

[5]Sara E. Mazzoni, Sarah E. Brewer, Jennifer L. Pyrzanowski, M. Josh Durfee,L. Miriam Dickinson, Juliana G. Barnard, Amanda F. Dempsey, Sean T. O'Leary. Effect of a multi-modal intervention on immunization rates in obstetrics and gynecology clinics [J]. American Journal of Obstetrics and Gynecology, 2016, 214(5). 